Check for updates

Cite this: RSC Adv., 2018, 8, 25558

\title{
Chemically-defined lactose-based autoinduction medium for site-specific incorporation of non- canonical amino acids into proteins
}

\author{
Michael Muzika, $\uparrow^{a}$ Natali H. Muskat, $\varphi^{a}$ Shani Sarid, ${ }^{a}$ Oshrit Ben-David, ${ }^{a}$ \\ Ryan A. Mehl (D) ${ }^{\text {b }}$ and Eyal Arbely (D) *ac
}

Genetic code expansion technology enables the site-specific incorporation of dozens of non-canonical amino acids (NCAAs) into proteins expressed in live cells. The NCAAs can introduce various chemical functionalities into proteins, ranging from natural post-translational modifications, to spectroscopic probes and chemical handles for bioorthogonal reactions. These chemical groups provide powerful tools for structural, biochemical, and biophysical studies, which may require significant quantities of recombinantly expressed proteins. NCAAs are usually encoded by an in-frame stop codon, such as the TAG (amber) stop codon, which leads to the expression of C-terminally truncated proteins. In addition, the incubation medium should be supplemented with the NCAA at a final concentration of 1-10 mM, which may be challenging when the availability of the NCAA is limited. Hence, bacterial expression of proteins carrying NCAAs can benefit from improvement in protein yield per given amount of added NCAA. Here, we demonstrate the applicability of an optimized chemically-defined lactose-based autoinduction (AI) medium to the expression of proteins carrying a NCAA, using the archaeal pyrrolysyltRNA synthetase/tRNA pair from the Methanosarcina genus. Per given amount of added NCAA, the use of Al medium improved protein expression levels by up to 3-fold, compared to IPTG induction, without an increase in misincorporation of canonical amino acids in response to the in-frame stop codon. The suggested medium composition can be used with various Escherichia coli variants transformed with different expression vectors and incubated at different temperatures.

Received 22nd May 2018 Accepted 8th July 2018

DOI: $10.1039 / \mathrm{c} 8 \mathrm{ra0} 4359 \mathrm{k}$

rsc.li/rsc-advances the NCAA by an exogenous aminoacyl-tRNA synthetase (aaRS), both orthogonal to endogenous tRNAs, aaRSs and canonical amino acids. Two frequently used orthogonal aaRS/tRNA pairs are the Methanocaldococcus jannaschii tyrosyl-tRNA synthetase/ tRNA $^{\text {Tyr }}$ pair, and the archaeal pyrrolysyl-tRNA synthetase/ tRNA $^{\text {Pyl }}$ (PylRS/tRNA ${ }_{\mathrm{CUA}}^{\mathrm{Pyl}}$ ) pair from the Methanosarcina genus (e.g., Methanosarcina barkeri and mazei species) ${ }^{8,9}$ Dozens of aaRSs have been evolved to recognise and aminoacylate their cognate tRNAs with various NCAAs carrying unique chemical groups ranging from post-translational modifications to photolabile protecting groups, and functional groups for bioorthogonal labeling. ${ }^{3,4}$ As of today, this technology has been realized in bacteria, yeast, cultured mammalian cells, Arabidopsis thaliana, and other multicellular organisms. ${ }^{10-14}$

Expression of recombinant proteins in bacteria is fundamental to biochemical, biophysical and structural studies. Genetic encoding of NCAAs is of particular importance to such studies, as it enables the site-specific modification of proteins with 'tailor-made' functional groups. Unless the host organism was engineered to synthesize the NCAA ${ }^{15}$ expression of modified proteins requires the addition of the NCAA to the growth medium at $1-10 \mathrm{mM}$ concentration range. However, in many cases the availability of the NCAA is limited. In addition, 
encoding the NCAA with an in-frame stop codon leads to the expression of C-terminally truncated proteins, which can significantly reduce overall protein yield. Hence, expression of recombinant proteins carrying a NCAA can benefit from methodologies that improve protein expression levels per given amount of NCAA added to the medium. That said, over the years several advances have been made on that front. For example, in Escherichia coli (E. coli) the use of genome engineering to replace genomic TAG codons with other stop codons, along with knockout of bacterial release factor 1 (RF-1), have significantly improved amber suppression efficiency and protein expression levels. ${ }^{16-18}$

One way to improve recombinant protein expression yield in bacteria is to use media that supports the growth of high celldensity cultures, such as chemically-defined auto-induction (AI) media. ${ }^{\mathbf{1 9}, 20}$ Protein expression in $E$. coli cultured in AI medium is based on diauxic bacterial growth: during the first phase, culture growth is supported by utilization of preferred carbon substrates such as glucose; in the second phase, and at low glucose concentrations, other carbon sources such as glycerol and lactose (or arabinose) are used, while the latter also serves as the inducer for lac (or ara, respectively) operon-controlled protein expression. The presence of glucose in AI media also prevents the uptake of lactose and represses expression of proteins controlled by the lac operon. Following glucose depletion, glycerol can serve as an effective carbon and energy source. However, glycerol-based metabolism may reduce the $\mathrm{pH}$ of culture media to a level that can stop culture growth. In contrast, metabolism of amino acids and organic acids with relatively high $\mathrm{p} K_{\mathrm{a}}$ (such as succinate) can reduce medium acidification. ${ }^{20}$ Thus, bacteria cultured in such media may reach high cell density, and a fine balance between medium components and different carbon sources can support the growth of protein-expressing bacteria that undergo 'autoinduction' at a certain culture density, when glucose depletion allows lactose-induction of protein expression. ${ }^{\mathbf{1 9 , 2 0}}$ It is important to note that this leads to an added advantage of AI media; protein expression is made easier and more reproducible, as there is no need to monitor the culture $\mathrm{OD}_{600}$.

AI media can be divided into two classes: chemically-defined and non-defined AI media. The former enables fine-tuning of amino acid composition and growth conditions for highdensity cultures, as well as expression of proteins labeled with selenomethionine. ${ }^{\mathbf{2 0 , 2 1}}$ Complete control over amino acid composition can be important for expression of proteins with NCAAs, as it eliminates potential misincorporation of canonical amino acids by promiscuous synthetases. ${ }^{22-26}$ That said, current evolved synthetases display high fidelity (ability to discriminate against canonical amino acids) in the presence of the NCAA. Low fidelity is often observed when proteins are expressed in the absence of the NCAA, particularly when permissive synthetases (capable of recognising more than one NCAA) are used. As the evolution of an aaRS is dependent on selection conditions, ${ }^{25}$ the ability to eliminate specific canonical amino acids from the selection medium (as in chemically-defined AI media) may enable the isolation of efficient aaRS with high fidelity, as long as the same amino acids are eliminated from the expression media. Importantly, protein expression in chemically-defined AI media usually provides superior yields. Therefore, it may improve protein yield per given amount of NCAA in particular, and medium volume in general, when compared to regular media. Indeed, proteins carrying NCAAs have been expressed in E. coli incubated in AI media, ${ }^{17,27,28}$ and arabinose-based chemically-defined AI media was optimized for NCAAincorporation by the Methanocaldococcus jannaschii tyrosyltRNA synthetase/tRNA ${ }^{\text {Tyr }}$ pair. ${ }^{29}$ However, the applicability of chemically-defined lactose-based AI media for protein expression using the PylRS/PylT pair has never been demonstrated.

One of the most frequently used bacterial expression systems is based on T7 RNA polymerase expression from an inducible promoter, such as the lacUV5. ${ }^{30}$ Induction is usually realized by the addition of isopropyl $\beta$-D-1-thiogalactopyranoside (IPTG), although it has been shown that lactose can also be used as an inducer. ${ }^{31}$ Many commercially available $E$. coli strains support the expression of proteins using lactose-inducible promoter based systems; e.g., BL21(DE3), B834(DE3), Origami ${ }^{\mathrm{TM}}$, Lemo21 ${ }^{\mathrm{TM}}$, and Rosetta ${ }^{\mathrm{TM}}$. Moreover, two RF-1 knockout BL21(DE3) strains, B-95. $\Delta \mathrm{A}$ and $\mathrm{B}-95 . \Delta \mathrm{A} \Delta \mathrm{fabR}$, have been created to allow superior expression levels of proteins with NCAAs at $37^{\circ} \mathrm{C}$ and low temperatures, respectively. ${ }^{17}$ Hence, the use of lactose-based chemically-defined AI media for NCAA incorporation using the PylRS/tRNA ${ }_{\text {CUA }}^{\text {Pyl }}$ pair can improve protein expression levels in this array of bacterial strains. Here we describe an optimized chemically-defined AI medium composition for high protein expression levels per given amount of supplemented NCAA, with no negative effect on the fidelity of the aaRS/tRNA $\mathrm{Cy}$ CuA pair. We also demonstrate the applicability of the suggested AI medium to different NCAAs, expressed proteins, expression plasmids, incubation temperatures, and E. coli strains (including an RF-1 knockout strain). As an example for AI medium lacking specific amino acids, we eliminated lysine and glutamine, without negatively affecting protein expression levels. Overall, the suggested chemicallydefined lactose-based AI medium improved protein yield per given amount of NCAA by up to 3-fold, when cultures were incubated for $24 \mathrm{~h}$ at $37^{\circ} \mathrm{C}$.

\section{Methods}

\section{Reagents}

Most chemicals were purchased from Sigma Aldrich (Darmstadt, Germany). $N \varepsilon$-[(tert-Butoxy)carbonyl]-L-lysine (1) and $N \varepsilon^{-}$ acetyl-L-lysine (2) were purchased from Chem-Impex International Inc. (Wood Dale, IL, USA) and used without further purification. BL21(DE3) E. coli strain (NEB, Ipswich, MA, USA) was used for protein expression. Primary anti- $6 \times$ His antibody (\#G020) and secondary anti-mouse IgG antibody (\#ab7068) were purchased from abm (Richmond, Canada) and Abcam (Cambridge, UK), respectively.

\section{Chemically-defined lactose-based autoinduction medium preparation}

The composition of the final chemically-defined lactose-based AI medium for expression of proteins with site-specifically 
Table 1 Autoinduction medium. Chemically-defined lactose-based Al medium for the site-specific incorporation of NCAAs into proteins expressed in E. coli, using the PyIRS/tRNACUA pair

\begin{tabular}{|c|c|c|c|}
\hline Glycerol $^{a}$ & $10 \%(\mathrm{w} / \mathrm{v})$ & $1: 20$ & $0.5 \%(\mathrm{w} / \mathrm{v})$ \\
\hline Glucose $\mathrm{e}^{a}$ & $37.5 \%(\mathrm{w} / \mathrm{v})$ & $1: 500$ & $0.075 \%(\mathrm{w} / \mathrm{v})$ \\
\hline $\mathrm{MgSO}_{4}$ & $1 \mathrm{M}$ & $1: 500$ & $2 \mathrm{mM}$ \\
\hline $\begin{array}{l}\text { Monosodium succinate }(\mathrm{pH} \\
=6.8)\end{array}$ & $17.5 \%(\mathrm{w} / \mathrm{v})$ & $1: 40$ & $0.438 \%(\mathrm{w} / \mathrm{v})$ \\
\hline $\mathrm{NH}_{4} \mathrm{Cl}$ & $1 \mathrm{M}$ & $1: 20$ & $50 \mathrm{mM}$ \\
\hline $\mathrm{Na}_{2} \mathrm{SO}_{4}$ & $0.1 \mathrm{M}$ & $1: 20$ & $5 \mathrm{mM}$ \\
\hline Trace metals ${ }^{c}$ & Variable & $1: 5000$ & Variable \\
\hline Amino acids ${ }^{d}$ & $5 \mathrm{mg} \mathrm{mL}^{-1}$ (each) & $1: 25$ & $0.2 \mathrm{mg} \mathrm{mL}^{-1}$ (each) \\
\hline
\end{tabular}

${ }^{a}$ Concentration of carbon sources was adjusted as described in the Results section. ${ }^{b}$ Hereafter simply referred to as lactose. ${ }^{c}$ See Table 2 for list of trace metals. ${ }^{d}$ Stock solution of amino acids was prepared as described in Methods section.

incorporated NCAA is described in Table 1. The composition of the $\times 5000$ trace-metal stock solution is as described in Table 2 . The stock solution of amino acids was prepared by dissolving $500 \mathrm{mg}$ of each of the L-amino acids in $100 \mathrm{~mL}$ deionized water in the following order (glutamine and lysine were omitted from the final AI medium): sodium glutamate; lysine $\cdot \mathrm{HCl}$; arginine $\cdot \mathrm{HCl}$; histidine $\cdot \mathrm{HCl} \cdot \mathrm{H}_{2} \mathrm{O}$; free aspartic acid; alanine; proline; glycine; threonine; serine; glutamine; asparagine $\cdot \mathrm{H}_{2} \mathrm{O}$; valine; leucine; isoleucine; phenylalanine; tryptophan; methionine. The solution was stirred until each amino acid was fully dissolved before adding the next one. This $\times 25$ amino acid stock solution did not contain cysteine and tyrosine. Additional $\times 25$ amino acid stock solutions were prepared in a similar way, each time omitting lysine, glutamine, or both lysine and glutamine.

\section{Protein expression}

In all experiments (except those described in Fig. 6C), competent $E$. coli cells were transformed with plasmid system A, composed of a $\mathrm{pBK}$ vector carrying the aaRS gene (Fig. 1A, vector a, kindly provided by Dr Jason W. Chin, Cambridge, UK) and a pCDF vector encoding the U25C mutant of tRNA ${ }_{\text {CUA }}^{\text {Pyl }}$ and C-terminally $6 \times$ Histagged super-folder green fluorescent protein (sfGFP) bearing an amber stop codon at position 150 (Fig. 1A, vector b). The

Table 2 Trace metal stock solution ${ }^{a}$

\begin{tabular}{lll}
\hline Salt & Stock concentration & Final concentration \\
\hline $\mathrm{FeCl}_{3}$ & $50 \mathrm{mM}$ & $10 \mu \mathrm{M}$ \\
$\mathrm{CaCl}_{2}$ & $20 \mathrm{mM}$ & $4 \mu \mathrm{M}$ \\
$\mathrm{MnCl}_{2}$ & $10 \mathrm{mM}$ & $2 \mu \mathrm{M}$ \\
$\mathrm{ZnSO}_{4}$ & $10 \mathrm{mM}$ & $2 \mu \mathrm{M}$ \\
$\mathrm{CoCl}_{2}$ & $2 \mathrm{mM}$ & $0.4 \mu \mathrm{M}$ \\
$\mathrm{CuCl}_{2}$ & $2 \mathrm{mM}$ & $0.4 \mu \mathrm{M}$ \\
$\mathrm{NiCl}_{2}$ & $2 \mathrm{mM}$ & $0.4 \mu \mathrm{M}$ \\
$\mathrm{Na}_{2} \mathrm{MoO}_{4}$ & $2 \mathrm{mM}$ & $0.4 \mu \mathrm{M}$ \\
$\mathrm{Na}_{2} \mathrm{SeO}_{3}$ & $2 \mathrm{mM}$ & $0.4 \mu \mathrm{M}$ \\
$\mathrm{H}_{3} \mathrm{BO}_{3}$ & $2 \mathrm{mM}$ & $0.4 \mu \mathrm{M}$
\end{tabular}

${ }^{a}$ Trace metal stock solution was filter-sterilized and used at $1: 5000$ dilution. expression of acetylated p53 and STAT3 described in Fig. 6C, was performed using plasmid system $B$. In this system, a pDule vector is used for the expression of aaRS and tRNA $\mathrm{CyU}_{\mathrm{CU}}^{\mathrm{Pl}}$ (Fig. 1A, vector $\mathrm{c}$ ),

A.

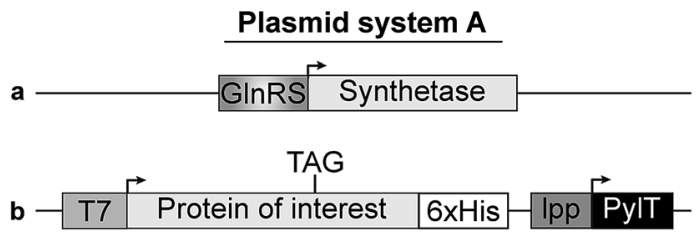

Plasmid system B

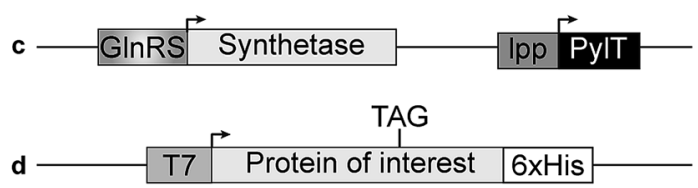

B.<smiles>CC(C)(C)OC(=O)NCCCC[C@H](N)C(=O)O</smiles><smiles>CC(=O)NCCCC[C@H](N)C(=O)O</smiles>

Fig. 1 Expression vectors and NCAA structure. (A) Two plasmid systems were used for bacterial expression of proteins with a sitespecifically incorporated NCAA. In plasmid system A, the aaRS is cloned on a pBK vector (plasmid a), while the protein of interest with an in-frame stop codon is cloned on a specialized $p C D F$ vector along with the pylT gene for the transcription of tRNA ${ }_{C U A}^{P y}$ (plasmid b). In plasmid system B, the NCAA-specific pyIRS variant and pylT are cloned on the same plasmid (pDule vector, ${ }^{15}$ plasmid $\mathrm{c}$ ) and the protein of interest is expressed using a pCDF vector (plasmid d). (B) Chemical structures of $N \varepsilon^{-}$[(tert-butoxy)carbonyl]-L-lysine (1) and $N \varepsilon$-acetyl-L-lysine (2). 
while the TAG-mutant of the protein of interest is encoded on a pCDF vector, simplifying the expression of different proteins (Fig. 1A, vector d). Transformed bacteria were incubated over night at $37{ }^{\circ} \mathrm{C}$ in $2 \times \mathrm{TY}$ medium supplemented with $50 \mu \mathrm{g} \mathrm{mL}{ }^{-1}$ spectinomycin and $50 \mu \mathrm{g} \mathrm{mL} \mathrm{m}^{-1}$ kanamycin (plasmid system A), or $50 \mu \mathrm{g}$ $\mathrm{mL}^{-1}$ spectinomycin and $12.5 \mu \mathrm{g} \mathrm{mL}^{-1}$ tetracycline (plasmid system B). Over-night culture was diluted to $\mathrm{OD}_{600}=0.02$ in $10 \mathrm{~mL}$ AI medium supplemented with $25 \mu \mathrm{g} \mathrm{mL}{ }^{-1}$ spectinomycin and 50 $\mu \mathrm{g} \mathrm{mL}^{-1}$ kanamycin (plasmid system A), or $25 \mu \mathrm{g} \mathrm{mL}{ }^{-1}$ spectinomycin and $12.5 \mu \mathrm{g} \mathrm{mL}^{-1}$ tetracycline (plasmid system B). Bacteria were cultured in $50 \mathrm{~mL}$ flasks and incubated for $24 \mathrm{~h}$ at $37{ }^{\circ} \mathrm{C}$ with agitation $(220 \mathrm{rpm})$ before analysis. Where indicated, medium was supplemented with $1 \mathrm{mM}$ of $N \varepsilon$-[(tert-butoxy) carbonyl]-L-lysine (Fig. 1B, 1) or $10 \mathrm{mM}$ of $N \varepsilon$-acetyl-L-lysine (Fig. 1B, 2) and nicotinamide (10-20 mM, to inhibit the catalytic activity of endogenous deacetylase, CobB). For protein expression in non-AI medium, over-night culture was diluted to $\mathrm{OD}_{600}=0.01$ in $25 \mathrm{~mL}$ of $2 \times$ TY supplemented with $25 \mu \mathrm{g} \mathrm{mL}{ }^{-1}$ spectinomycin and $25 \mu \mathrm{g} \mathrm{mL} \mathrm{m}^{-1}$ kanamycin and, where indicated, medium was also supplemented with $\mathbf{1}$ or $\mathbf{2}$ as described for AI medium. Bacteria were incubated in a $100 \mathrm{~mL}$ flask at $37{ }^{\circ} \mathrm{C}$ with agitation $(220 \mathrm{rpm})$ until $\mathrm{OD}_{600}=0.6$, when protein expression was induced with $1 \mathrm{mM}$ IPTG. The induced culture was incubated at $37{ }^{\circ} \mathrm{C}$ for 14-16 h.

\section{Measurement of sfGFP fluorescence}

Bacteria from $500 \mu \mathrm{L}$ of culture were centrifuged and resuspended in $500 \mu \mathrm{L}$ of phosphate buffered saline (PBS). Samples were then diluted in PBS and $\mathrm{OD}_{600}$ as well as sfGFP fluorescence (excitation $485 \mathrm{~nm}$, emission $510 \mathrm{~nm}$ ) were measured in a 96 well plate format. Triplicates were measured using three independent transformations. As background, $\mathrm{OD}_{600}$ and fluorescence intensity were also measured for bacteria transformed with an empty vector b. Fluorescence intensity $(F)$ is reported after subtraction of background fluorescence according to eqn (1).

$$
F=F_{\text {Sample }}-\left(\mathrm{OD}_{\text {Sample }} \times \frac{F_{\text {Background }}}{\text { OD }_{\text {Background }}}\right)
$$

\section{Western blot analysis}

Bacteria from $1 \mathrm{~mL}$ of culture incubated for $24 \mathrm{~h}$ in $\mathrm{AI}$ medium, or 14-16 h in $2 \times$ TY medium supplemented with IPTG, were lysed in $1 \times$ Laemmli sample buffer by heating to $95{ }^{\circ} \mathrm{C}$ for $5 \mathrm{~min}$, mixing and repeating the heating step. The lysate was then clarified by centrifugation. To compare the level of protein expression relative to culture volume, equal volumes of cleared cell-lysates were analysed in each lane. Proteins were separated by SDS gel electrophoresis and transferred to $0.2 \mu \mathrm{m}$ nitrocellulose membrane using semi-dry transfer apparatus (Bio Rad, Trans-Blot Turbo). The membrane was blocked for $1 \mathrm{~h}$ with Tris-buffered saline containing $0.1 \%(\mathrm{v} / \mathrm{v})$ Tween-20 (TBST) and 5\% (w/v) non-fat dry milk, followed by an overnight incubation with anti- $6 \times$ His antibody at $4{ }^{\circ} \mathrm{C}$. After incubation at room temperature with horseradish peroxidase-conjugated secondary antibody, proteins were visualized using enhanced chemiluminescence reagent (GE Healthcare). Immunoblot intensities were quantified with Image.$^{32}$

\section{Mass spectrometry}

Proteins were expressed in E. coli BL21(DE3) strain incubated with $1 \mathrm{mM}$ of 1 as described above. Bacteria were resuspended in lysis buffer $(20 \mathrm{mM}$ Tris $\mathrm{pH}=8,300 \mathrm{mM} \mathrm{NaCl}, 10 \mathrm{mM}$ imidazole, $0.05 \% \mathrm{v} / \mathrm{v} \beta$-mercaptoethanol) supplemented with protease inhibitors $\left(1.2 \mathrm{mg} \mathrm{mL}^{-1}\right.$ leupeptin, $1 \mathrm{mM}$ pepstatin A, $100 \mathrm{mM}$ phenylmethylsulfonyl fluoride (PMSF) and $1 \mathrm{mg} \mathrm{mL}$ aprotinin) and lysed by sonication. The lysate was clarified by centrifugation (16 $000 \mathrm{~g}, 4^{\circ} \mathrm{C}, 30 \mathrm{~min}$ ), and the supernatant was loaded on a $1 \mathrm{~mL}$ HisTrap column (GE Healthcare) and washed with lysis buffer. Protein was eluted with elution buffer $(20 \mathrm{mM}$ Tris $\mathrm{pH}=8,100 \mathrm{mM} \mathrm{NaCl}, 300 \mathrm{mM}$ imidazole, $0.05 \% \mathrm{v} / \mathrm{v} \beta$ mercaptoethanol, $10 \% \mathrm{v} / \mathrm{v}$ glycerol), following a linear gradient over 20 column volumes, with fractionation. Combined fractions were pooled and concentrated using an Amicon Ultra-15 (3 kDa cutoff, Merck). The concentrated sample was diluted tenfold with anion loading buffer (20 mM Tris $\mathrm{pH}=8)$ and loaded on a $5 \mathrm{~mL}$ HiTrap Q column (GE Healthcare). Protein was eluted with a linear gradient ranging from 0 to $500 \mathrm{mM}$ $\mathrm{NaCl}$ over 35 column volumes, with fractionation. Combined fractions were concentrated as described above. Following buffer exchange to $50 \mathrm{mM}$ ammonium bicarbonate using $5 \mathrm{~mL}$ HiTrap desalting column (GE Healthcare), protein mass was measured by direct injection electrospray ionization mass spectrometry (ESI-MS, LCQ Fleet, Thermo Scientific). Protein concentration was determined by an absorption measurement at $488 \mathrm{~nm}$ (extinction coefficient $\left.=8.33 \times 10^{4} \mathrm{M}^{-1} \mathrm{~cm}^{-1}\right) \cdot{ }^{33}$

\section{Results}

In the process of adapting the lactose-based chemically-defined AI media for NCAA incorporation we used plasmid system A (Fig. 1A). As a model protein, we used C-terminally $6 \times$ His-tagged sfGFP with an in-frame amber stop codon mutation at position 150. ${ }^{33}$ sfGFP-150TAG, hereafter simply termed sfGFP, was expressed along with $M$. barkeri wild-type PylRS and its cognate tRNA $A_{\text {PUA }}^{\mathrm{yl}}$ in transformed E. coli BL21(DE3) cells incubated in the presence of NCAA 1 (Fig. 1B), which is a known substrate of wildtype PylRS. As the C-terminally truncated protein $\left(\mathrm{sfGFP}_{1-149}\right)$ is non-fluorescent, both GFP fluorescence and Western blot analyses (using an antibody against the C-terminal $6 \times$ His-tag) report on overall protein expression levels.

\section{Concentration of carbon sources}

In a previous study describing bacterial expression of proteins with a site-specifically incorporated NCAA in AI media, leucine and aspartate were used for metabolic control of $\mathrm{pH} .{ }^{29}$ As observed by Studier F.W., succinate allows for higher protein expression levels compared to leucine and aspartate, so it was used here at a final concentration of $0.438 \%(\mathrm{w} / \mathrm{v}) .{ }^{20}$ We then measured the effect of energy sources and their concentration on culture density and protein expression levels (Fig. 2). 
A.

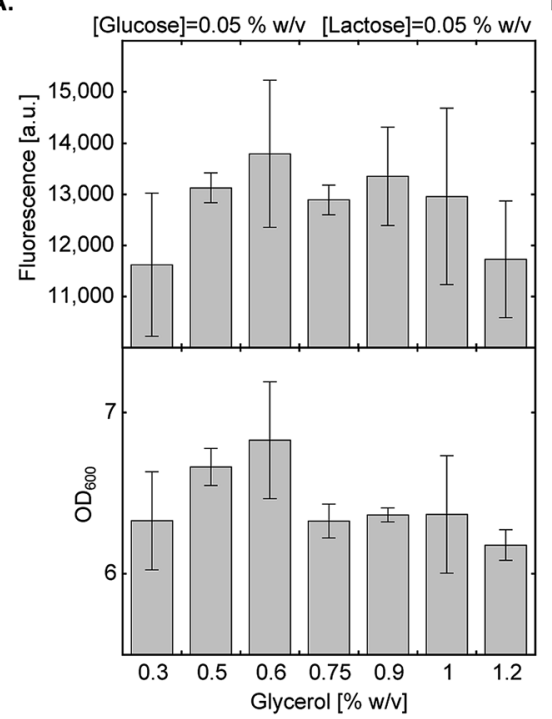

B.

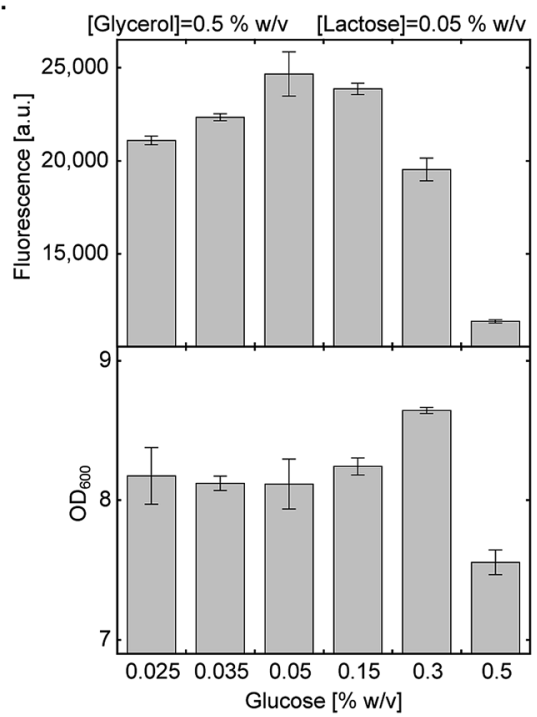

c.

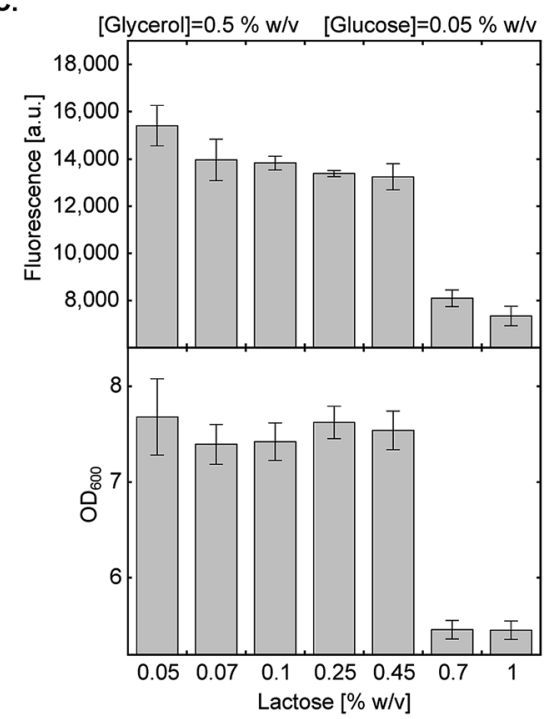

Fig. 2 Effect of carbon source composition on protein expression in Al medium. Expression levels of sfGFP ${ }^{150 B o c L y s}$ in BL21(DE3) cells transformed with plasmid system A (Fig. 1A) and incubated in chemically-defined Al media supplemented with 1 ( 1 mM) and indicated concentrations of carbon sources. Average values are presented $\pm \mathrm{SD}, n=3$. (A) Fluorescence intensity as a function of glycerol concentration. [glucose] $=$ $0.05 \%(\mathrm{w} / \mathrm{v})$, [lactose] $=0.05 \%(\mathrm{w} / \mathrm{v})$. (B) Fluorescence intensity as a function of glucose concentration. [glycerol] $=0.5 \%(\mathrm{w} / \mathrm{v})$, [lactose] $=0.05 \%$ $(\mathrm{w} / \mathrm{v})$. (C) Fluorescence intensity as a function of lactose concentration. [glycerol] $=0.5 \%(\mathrm{w} / \mathrm{v})$, [glucose] $=0.05 \%(\mathrm{w} / \mathrm{v})$.

We first tested the effect of glycerol concentration by keeping glucose and lactose concentrations at $0.05 \%$ (w/v) (Fig. 2A). Glycerol concentration within the range of $0.3-1.2 \%(\mathrm{w} / \mathrm{v})$ had no statistically significant effect on culture density and expression levels of full-length sfGFP ${ }^{150 B o c L y s}$. We therefore decided to follow the original protocol suggested by Studier F. W. and kept glycerol concentration at $0.5 \%(\mathrm{w} / \mathrm{v}) .{ }^{20} \mathrm{Next}$, we examined the effect of glucose concentration within the range of $0.025-0.5 \%$ $(\mathrm{w} / \mathrm{v})$, while keeping glycerol and lactose concentrations at $0.5 \%$ $(\mathrm{w} / \mathrm{v})$ and $0.05 \%(\mathrm{w} / \mathrm{v})$, respectively (Fig. 2B). High glucose concentration of $0.5 \%(\mathrm{w} / \mathrm{v})$ inhibited culture growth and protein expression. Glucose concentration of $0.3 \%(\mathrm{w} / \mathrm{v})$ enabled culture growth to higher density, but overall protein yield was lower, compared to $0.05 \%$ glucose. Relatively high protein yield was obtained between $0.05 \%$ and $0.15 \%(\mathrm{w} / \mathrm{v})$ glucose concentration. Finally, we measured the effect of lactose concentration on culture density and expression levels of $\operatorname{sfGFP}^{150 \text { BocLys }}$ (Fig. 2C). Within the range of $0.05-1.00 \%(\mathrm{w} / \mathrm{v})$ lactose, lowest culture density and sfGFP $^{150 B o c L y s}$ expression were measured at $0.70 \%$ and $1.00 \%(\mathrm{w} / \mathrm{v})$ lactose. Culture density was similar within the range of $0.05 \%$ and $0.45 \%(\mathrm{w} / \mathrm{v})$ lactose, while protein expression was slightly higher within the lower range of lactose concentrations.

\section{Fine-tuning of glucose:lactose ratio}

As glycerol only supports culture growth at late stages and had minimal inhibitory effect on the lac operon, ${ }^{20}$ we decided to finetune the ratio between glucose and lactose which may have a more pronounced effect on overall protein yield. We found that at $0.05 \%(\mathrm{w} / \mathrm{v})$ lactose, increasing glucose concentration from $0.05 \%$ to $0.075 \%(\mathrm{w} / \mathrm{v})$ marginally improved both culture density and expression of $\operatorname{sfGFP}^{150 \text { BocLys }}$ (Fig. 3A). At this concentration of glucose, decreasing lactose concentration below $0.05 \%(\mathrm{w} / \mathrm{v})$ had a negative impact on protein expression levels. To verify that the highest protein expression level is obtained at a glucose:lactose ratio of $0.075 \%: 0.05 \%(\mathrm{w} / \mathrm{v})$, we measured $\mathrm{sfGFP}^{150 \text { BocLys }}$ expression in an array of 17 different lactose-based chemically-defined AI medium compositions by varying concentrations of glucose and lactose (Fig. 3B). In all expression tests, glycerol concentration was kept at $0.5 \%(\mathrm{w} / \mathrm{v})$, and the array was designed around medium composition of $0.05 \%(\mathrm{w} / \mathrm{v})$ glucose and lactose concentrations. Expression levels of sfGFP $^{150 \text { BocLys }}$ in all 17 conditions confirmed that a glucose to lactose ratio of 0.075\%:0.05\% (w/v) allows for relatively high protein expression levels within a semi-plateau region, which ensures consistent and reproducible results (Fig. 3B).

\section{Protein expression in lysine and glutamine free medium}

Strict negative selection during the evolution of aaRSs, together with MS analyses to validate the fidelity of the evolved aaRS, ensure that misincorporation is not preferred when proteins are expressed in the presence of the NCAA (i.e., misincorporation is observed when proteins are expressed in the absence of the NCAA). However, promiscuous aaRSs that were disqualified due to low fidelity may benefit from the use of culture medium that lacks specific canonical amino acids. One of the advantages of a chemically-defined medium, is that it allows complete control over the composition of the growth medium. To demonstrate the use of non-complete AI media, we excluded lysine and glutamine from the chemically-defined AI medium. As seen in Fig. 4A, protein expression levels in the presence of $\mathbf{1}$ were not reduced when bacteria were incubated in the absence of lysine, glutamine or both lysine and glutamine. In addition, when sfGFP $^{150 B o c L y s}$ was expressed in the absence of $\mathbf{1}$, protein expression levels were 
A.

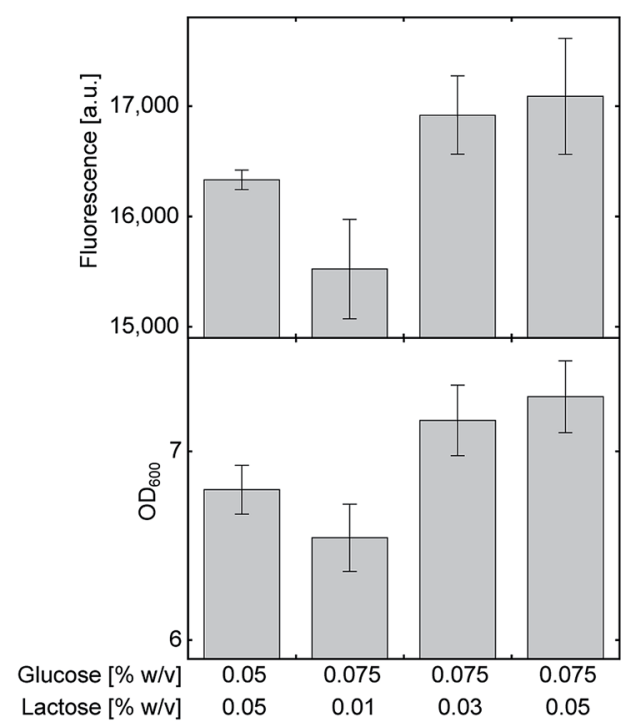

B.

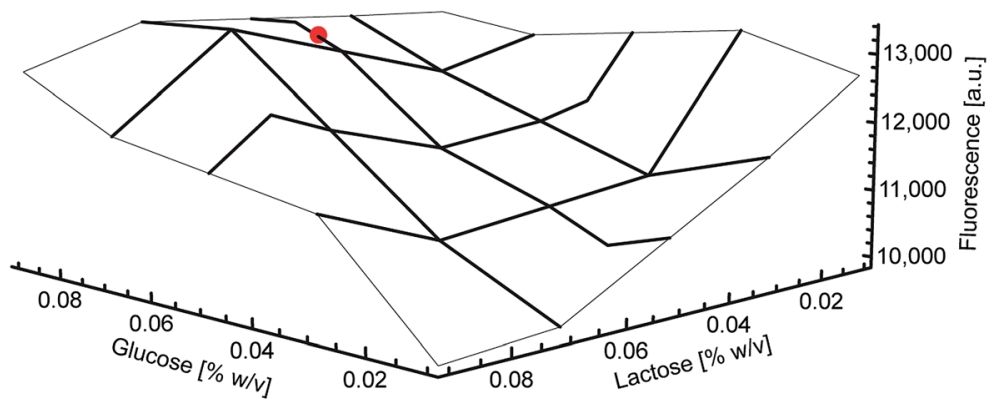

Fig. 3 Fine-tuning of glucose and lactose concentrations. (A) E. coli BL21(DE3) cells transformed with plasmid system A (Fig. 1A) were incubated in chemically-defined Al media supplemented with $1(1 \mathrm{mM}), 0.5 \%(\mathrm{w} / \mathrm{v})$ glycerol, and indicated concentrations of glucose and lactose. The highest expression level of sfGFP ${ }^{150 B o c L y s}$ was obtained when transformed bacteria were incubated in chemically-defined Al medium supplemented with $0.075 \%(\mathrm{w} / \mathrm{v})$ glucose and $0.05 \%(\mathrm{w} / \mathrm{v})$ lactose. Average values are presented $\pm \mathrm{SD}, n=3$. (B) The final concentration as well as the ratio between glucose and lactose were verified using a small-scale expression media array. Chemically-defined Al media were supplemented with $1(1 \mathrm{mM}), 0.5 \%(\mathrm{w} / \mathrm{v})$ glycerol and $0.01-0.09 \%(\mathrm{w} / \mathrm{v})$ of glucose and lactose. The chosen optimal condition for expression of proteins with genetically encoded NCAA $[0.5 \%(\mathrm{w} / \mathrm{v})$ glycerol, $0.075 \%(\mathrm{w} / \mathrm{v})$ glucose, $0.05 \%(\mathrm{w} / \mathrm{v})$ lactose] is marked with a red circle.

minimal, suggesting only basal level of misincorporation in the absence of the NCAA. In some measurements we have noticed a slight decrease in culture density when $\mathbf{1}$ was added to the AI medium (compared to AI medium without 1). This growth inhibition may be due to inaccurate correction of $\mathrm{pH}$ after the addition of 1 dissolved in $1 \mathrm{M} \mathrm{NaOH}$, over-expression of sfGFP, or both.

To further ensure the fidelity of PylRS expressed in E. coli cultured in chemically-defined lactose-based AI medium, we verified the incorporation of $\mathbf{1}$ into expressed sfGFP by ESI-MS. As seen in Fig. 4B, the total mass of ffGFP $^{150 B o c L y s}$ expressed in $2 \times$ TY (top, 27 943.2 Da) or chemically-defined lactose-based AI medium (bottom, 27 943.4 Da) was within error range from the expected mass of $27941.5 \mathrm{Da}$. Therefore, the fidelity of wild-type pyrrolysine tRNA synthetase was similar when sfGFP $^{150 \text { BocLys }}$ was expressed in $2 \times$ TY or chemically-defined lactose-based AI medium. Interestingly, we noticed that expression of sfGFP in chemically-defined lactose-based AI medium increased the extent of hydrolytic cleavage of the N-terminal methionine (27 811.8 Da, expected mass: 27 808.4 Da). It should be noted that divalent cations such as $\mathrm{Fe}^{(2+)}, \mathrm{Mn}^{(2+)}$, and $\mathrm{Co}^{(2+)}$ are cofactors of methionyl aminopeptidase, ${ }^{41,42}$ and that the AI medium is supplemented with several divalent cations. Finally, we followed protein expression levels and culture density as a function of time using BL21(DE3) incubated in the fine-tuned lysine- and glutamine-free chemically-defined lactose-based AI medium. As depicted in Fig. 4C, expression levels of sfGFP reached a plateau after approximately $24 \mathrm{~h}$ of incubation at $37^{\circ} \mathrm{C}$. We therefore conclude that lysine and glutamine can be omitted from the chemically-defined medium without negative effects on protein expression levels.

\section{Applicability to evolved aaRSs and other $E$. coli strains}

All optimization steps presented so far were performed using wild-type PylRS and NCAA 1 for the expression of SfGFP $P^{150 B o c L y s}$ in the E. coli BL21(DE3) strain. To verify the applicability of the chemically-defined lactose-based AI medium to other aaRSs and E. coli BL21(DE3) variants, we first compared between the fidelity of wild-type PylRS (aaRS 1, Fig. 5A) and eight evolved aaRSs (aaRSs 2-9). E. coli BL21(DE3) cells expressing sfGFP150TAG and indicated aaRSs were incubated in lactose-based AI medium without any NCAA (-). As a positive control we measured the expression levels of full-length sfGFP ${ }^{150 B o c L y s}$ in $E$. coli BL21(DE3) expressing wild-type PylRS and incubated in the presence of $1(+)$. Compared to the positive control, all aaRSs demonstrated residual protein expression levels. Thus, the fidelity of evolved aaRSs is similar to the fidelity of wild-type PylRS, when protein-expressing bacteria are incubated in our suggested AI media without the NCAA.

The E. coli BL21(DE3) strain is commonly used for the expression of recombinant proteins. That said, other commercially available $E$. coli BL21-based strains are often used for the expression of various proteins. For example, the Rosetta ${ }^{\mathrm{TM}}$ (DE3) strain (chloramphenicol resistant, Novagen) that supplies additional tRNAs for rare codons, or the tunable T7 expression strain Lemo21 ${ }^{\mathrm{TM}}(\mathrm{DE} 3)$ (chloramphenicol resistant, NEB). As seen in Fig. 5B, NCAA-dependent expression of sfGFP ${ }^{150 B o c L y s}$ was observed in these bacterial strains. However, protein expression levels in Lemo21(DE3) and especially Rosetta(DE3) were lower than expression levels in BL21(DE3). While expression levels in Lemo21(DE3) and Rosetta(DE3) may improve by 
A.

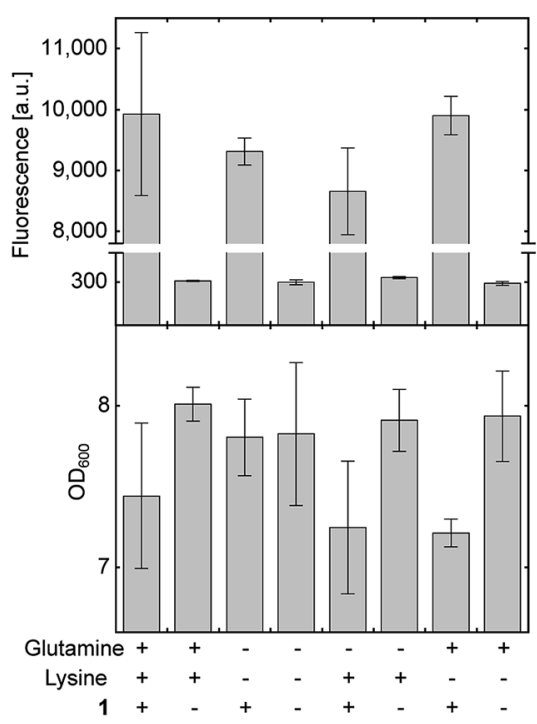

B.
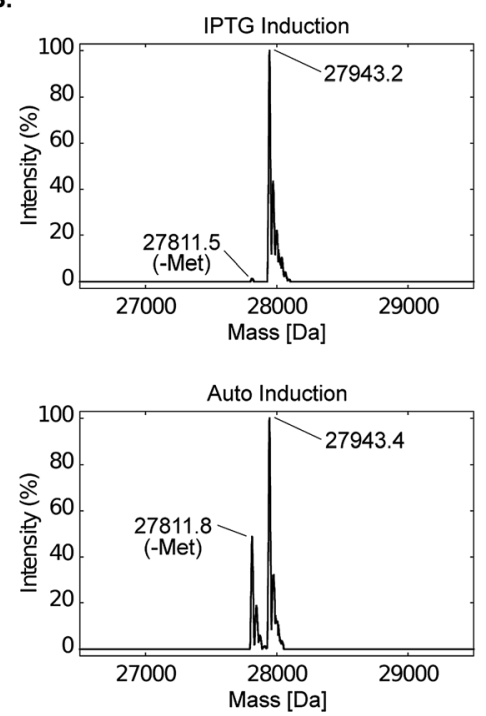

C.

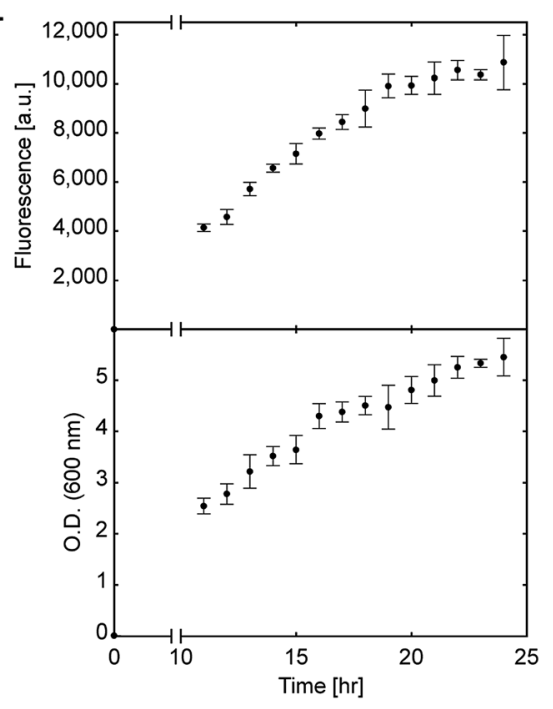

Fig. 4 Effect of amino acid composition and expression time on protein expression in chemically-defined lactose-based Al medium. (A) Transformed E. coli BL21(DE3) cells expressing sfGFP-150TAG and wild-type pyrrolysyl-tRNA synthetase/tRNA Pyl (using plasmid system A, Fig. 1A) were incubated in the fine-tuned chemically-defined lactose-based Al medium, or medium without lysine, without glutamine, or without lysine and glutamine. The effect of lysine and/or glutamine exclusion on protein expression levels was monitored by measuring sfGFP ${ }^{150 B o c L y s}$ expression in the presence $(+)$ or absence $(-)$ of $1(1 \mathrm{mM})$. Average values for biological replicates are presented $\pm S D, n=3$. (B) Total mass of sfGFP ${ }^{150 B o c L y s}$ expressed in E. coli BL21(DE3) cells incubated in 2xTY medium (IPTG induction), or fine-tuned chemically-defined lactose-based Al medium without lysine and glutamine; both media were supplemented with $1 \mathrm{mM}$ of 1 . Expected mass: 27941.5 Da. (C) sfGFP ${ }^{150 B o c L y s}$ fluorescence and $\mathrm{OD}_{600}$ measured as a function of time for $E$. coli BL21(DE3) cells transformed as described in A and incubated in fine-tuned chemically-defined lactose-based Al medium. Average values for biological replicates are presented $\pm S D, n=3$.

optimizing medium composition, we noted that expression levels of proteins carrying a NCAA are usually lower in these strains, compared to BL21(DE3), even when bacteria are incubated in $2 \times$ TY medium.

We also compared the expression levels of $\operatorname{sfGFP}^{150 A c L y s}$ in $E$. coli BL21(DE3) incubated in different lactose-based AI media supplemented with $N \varepsilon$-acetyl lysine (2, Fig. 5C). Protein expression levels in bacteria incubated in the AI medium suggested in the current study were higher than those measured in bacteria incubate in AI media suggested by Studier F. W. ${ }^{20}$ or Fox B. G. and Blommel P. G. ${ }^{19}$ (all media were not supplemented with vitamins). Hence, the suggested AI medium offers improved protein expression levels relative to lactose-based AI media compositions that were not optimized for NCAA incorporation.

\section{Improved protein expression levels in chemically-defined lactose-based AI medium}

One of the advantages in using chemically-defined AI medium is superior protein expression levels per given culture volume, relative to incubation in 'standard' medium. We therefore compared between protein expression levels in BL21(DE3) cells incubated in chemically-defined lactose-based AI medium and cells incubated in $2 \times$ TY (Fig. 6A). As an added measure, we used the evolved AcKRS3 synthetase for the incorporation of $2 .{ }^{34}$ Compared to NCAA 1, incorporation efficiency of 2 is usually lower, which requires a higher concentration of 2 in culture media. Thus, better expression levels of site-specifically acetylated proteins can aid studies of epigenetics and posttranslational modification by acetylation. As depicted in Fig. 6A, protein expression levels in chemicallydefined lactose-based AI medium were up to 3-fold higher compared to expression in $2 \times \mathrm{TY}$, when estimated from Western blots. In line with this observation, the yield of purified sfGFP ${ }^{150 B o c L y s}$ expressed in AI media was $81 \mathrm{mg}$ per liter of culture, compared to $41 \mathrm{mg}$ of protein per litre of $2 \times \mathrm{TY}$ culture. In addition, the increase in protein yield was not accompanied by an increase in residual expression in the absence of NCAA. Hence, amino acid misincorporation in the absence of NCAA, relative to protein yield in the presence of NCAA, was lower in our AI medium, compared to $2 \times \mathrm{TY}$ medium.

We have also compared between protein expression levels in bacteria incubated in AI media and IPTG-induced bacteria incubated in $2 \times \mathrm{TY}$, using the RF-1 knockout strain B-95. $\Delta \mathrm{A} \Delta$ fabR. ${ }^{17}$ Although protein expression levels in this strain are usually higher compared to BL21(DE3), higher density cultures can further improve protein yield per given amount of added NCAA. Indeed, when B-95. $\Delta \mathrm{A} \Delta \mathrm{fabR}$ were incubated at $37{ }^{\circ} \mathrm{C}$, protein expression in chemically-defined AI medium was significantly higher (Fig. 6B). However, when cells were incubated at $22{ }^{\circ} \mathrm{C}$ for $48 \mathrm{~h}$, no improvement in protein expression levels was observed. That said, at $22{ }^{\circ} \mathrm{C}$, expression level in the absence of the NCAA was lower in AI medium compared to $2 \times \mathrm{TY}$. Therefore, chemically-defined lactosebased AI medium without lysine and glutamine can improve 
A.

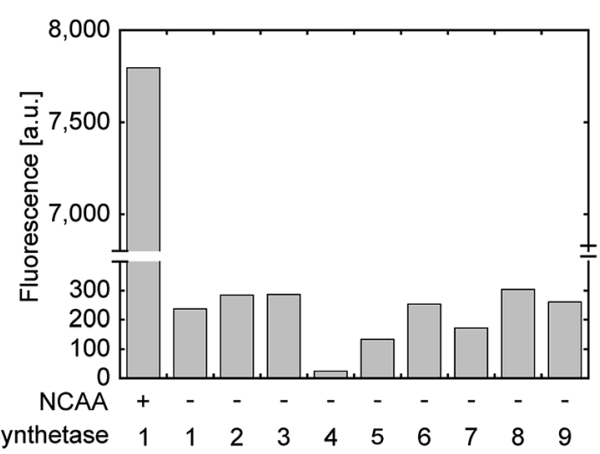

C.

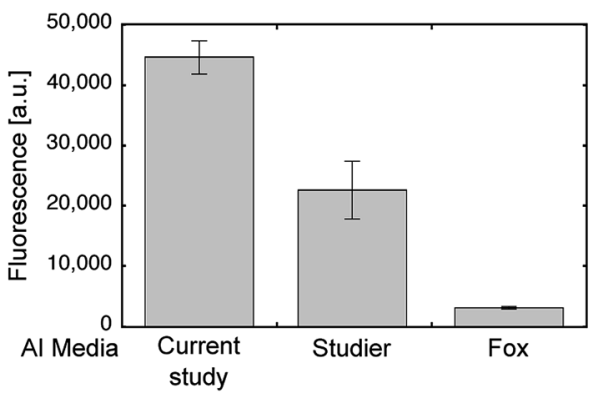

B.

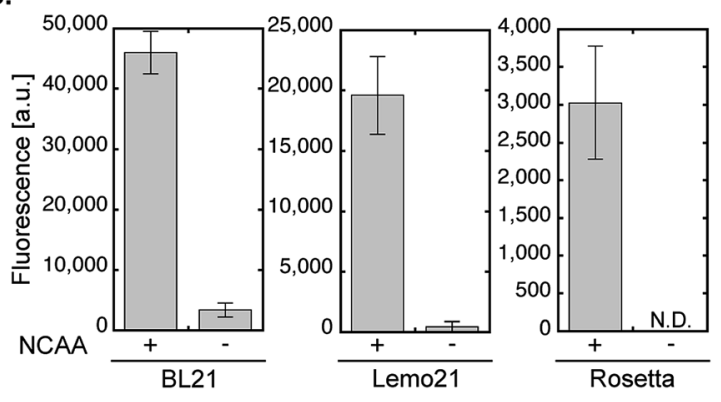

Fig. 5 aaRS fidelity and protein expression levels using evolved aaRSs and different E. coli strains or Al medium compositions. (A) To monitor the level of possible amino acid misincorporation by the amber suppression machinery, BL21(DE3) cells were transformed with plasmid system A and incubated in chemically-defined lactose-based Al media in the absence of 1 (-). Protein expression was quantified by measuring sfGFP ${ }^{150 B o c L y s}$ fluorescence in live bacteria. For comparison, sfGFP ${ }^{150 B o c L y s}$ fluorescence was measured in bacteria incubated in the presence of 1 ( + ). The aaRSs used in this study (names and mutations relative to wild-type PyIRS): 1 - M. barkeri wild-type synthetase; 2 - M. mazei wild-type synthetase; 3 AcKRS3 (M. barkeri L266M, L270I, Y271F, L274A, C313F); ${ }^{34} 4$ - AcKRS1 (M. barkeri L266V, L270I, Y271F, L274A, C313F); 35 - BCNRS (M. barkeri Y271M, L274G, C313A); ${ }^{36} 6$ - PCKRS (M. barkeri M241F, A267S, Y271C, L274M); 77 - ThzKRS (M. barkeri A267S, C313V, M315F, D344G);38 8 -

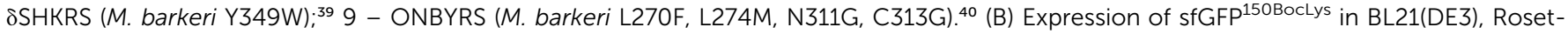
ta(DE3), or Lemo21(DE3) E. coli strains transformed as described in A and incubated for $24 \mathrm{~h}$ in chemically-defined lactose-based Al media with $(+)$ or without (-) 1. Protein expression levels were quantified by GFP fluorescence measurement. (C) Fluorescence of sfGFP ${ }^{150 A c L y s}$ expressed in BL21(DE3) incubated for $24 \mathrm{~h}$ in Al media suggested in the current study, Studier F. W., ${ }^{20}$ or Fox B. G. and Blommel P. G., ${ }^{19}$ and supplemented with 2. Average values for biological replicates are presented $\pm \mathrm{SD}, n=3$.

protein yield in the B-95. $\Delta \mathrm{A} \Delta f a b R$ RF-1 knockout strain and reduce possible amino acid misincorporation.

The expression tests presented above, were performed using plasmid system A and sfGFP-150TAG as a model protein. To demonstrate the broad applicability of the chemically-defined AI medium, we used plasmid system B (Fig. 1A) in order to express two proteins, site-specifically acetylated at biologically relevant positions: the signal transducer and activator of transcription 3 (STAT3) site-specifically acetylated at position Lys685, and the DNA binding domain of the tumour suppressor protein $\mathrm{p} 53$, site-specifically acetylated at position $120 .^{43-47}$ Acetylation of these lysine residues was shown to affect the transcriptional activity of STAT3 and p53, and as such, recombinant expression of the site-specifically acetylated proteins is important for in vitro acetylation-dependent functional and structural studies. In plasmid system B the genes required for amber suppression (the aaRS and pylT) are encoded on one plasmid (based on the pDule backbone), compared to plasmid system A that was used so far, where the gene of interest was encoded on a specialized plasmid carrying the pylT gene. Using plasmid system B we were able to express Lys685acetylated STAT3 and Lys120-acetylated p53 in BL21(DE3) incubated in chemically-defined lactose-based AI medium (Fig. 6C). While protein expression may be improved by optimizing the composition of the chemically-defined AI medium, data show that our suggested medium supports the expression of different acetylated proteins using the pDule expression vector. That said, expression levels of acetylated proteins using plasmid system A were approximately 5-fold higher, compared to plasmid system B (Fig. 6D). The difference in expression levels between these two plasmid systems is expected because the ratio of pyrrolysyl-tRNA synthetase/tRNA is higher with system A resulting in higher suppression efficiency. ${ }^{48}$

Taken together, we demonstrated improved expression level of proteins with genetically encoded NCAAs in modified chemically-defined lactose-based AI medium, using the pyrrolysyl-tRNA synthetase/tRNA $\mathrm{Cyl}$ pair. The suggested medium improved protein expression yield by up to 3 -fold without measurable effects on the fidelity of wild type PylRS and evolved aaRSs. Our data show that the medium can be used for the expression of different proteins using different $E$. coli strains, following an 'inoculate-and-forget' protocol. The composition of the suggested medium supports the expression of proteins using plasmid system A (pBK vector) or B (pDule 
A.

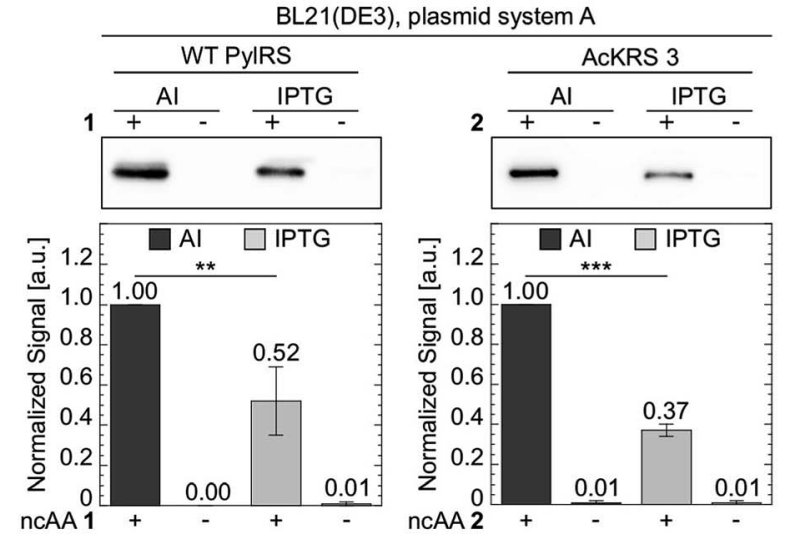

B.

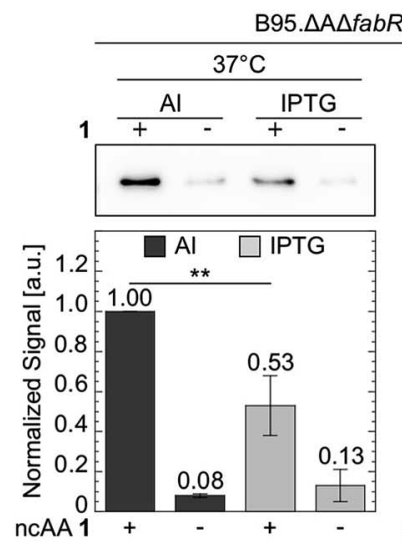

C.

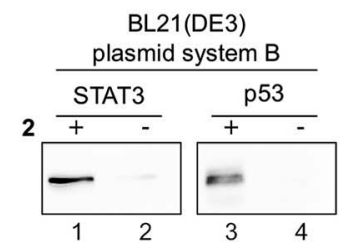

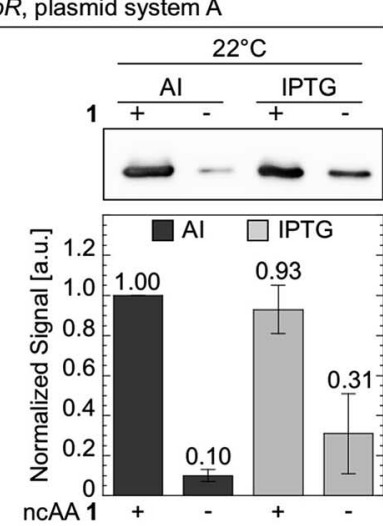

D.

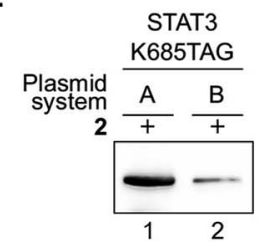

additional cloning steps. However, in our hands, protein expression levels using plasmid system A were higher, compared to plasmid system B.

Protein expression levels using medium without lysine and glutamine were similar to those measured in media supplemented with these two amino acids. Lysine and glutamine were chosen as an example, based on their structural similarity to pyrrolysine and its non-canonical derivatives. It may be interesting to check if aaRS evolution performed in chemically defined media lacking specific canonical amino acids can provide efficient and permissive aaRS without compromised fidelity.

Due to the ability of the chemically-defined medium to support higher culture density, using this medium significantly improved protein yield per given amount of NCAA, even when an RF-1 knockout strain was used. Considering the scarce availability of many NCAAs, protein expression using AI medium offers an attractive alternative to 'standard' growth media and IPTG induction protocols.

\section{Conflicts of interest}

There are conflicts to declare.

\section{Acknowledgements}

This work has received funding from the European Research Council (ERC) under the European Union's Horizon 2020 research and innovation programme under grant agreement No. 678461 (to EA), and from the Israel Science Foundation (grant number 807/15 to EA).

\section{References}

Fig. 6 Improved protein expression in chemically-defined lactosebased Al medium. To compare between protein expression levels, total protein extracts normalized by culture volume were analysed by Western blot and proteins were visualized using an antibody against the $\mathrm{C}$-terminal $6 \times$ His-tag. Representative membranes are shown for each set of experiments. Average values for biological replicates are presented $\pm S D, n \geq 3$. Statistical analysis was performed using Student's $t$-test (two-tailed, unpaired). $* P<0.05, * * P<0.01, * * * P<$ 0.001 . (A) sfGFP-150TAG expressed in E. coli BL21(DE3) cells transformed with plasmid system A (Fig. 1A) and incubated with NCAA 1 (left) or 2 (right). Expression was induced in chemically-defined lactose-based Al medium or by $1 \mathrm{mM} \mathrm{IPTG}$ in $2 \times \mathrm{TY}$ medium at $37^{\circ} \mathrm{C}$. (B) sfGFP-150TAG expressed in E. coli B-95. $\Delta$ A $\Delta$ fabR cells incubated with NCAA 1. Expression was induced in lactose-based Al medium or by $1 \mathrm{mM}$ IPTG in $2 \times \mathrm{TY}$ medium at 22 or $37{ }^{\circ} \mathrm{C}$. (C) Expression of Lys685-acetylated STAT3 and Lys120-acetylated p53 variants utilizing plasmid system B (Fig. 1A, plasmids $\mathrm{c}$ and d), in the E. coli BL21(DE3) strain incubated in Al medium supplemented with NCAA 2. (D) Western blot analysis of Lys685-acetylated STAT3 expressed using plasmid system A, or plasmid system B.

vector). The advantage of plasmid system $\mathrm{B}$ is that it allows convenient use of existing standard expression vectors (e.g., pET vectors) bearing only the target protein, and therefore saves

1 C. C. Liu and P. G. Schultz, Annu. Rev. Biochem., 2010, 79, 413-444.

2 J. W. Chin, Annu. Rev. Biochem., 2014, 83, 379-408.

3 A. Dumas, L. Lercher, C. D. Spicer and B. G. Davis, Chem. Sci., 2015, 6, 50-69.

4 W. Wan, J. M. Tharp and W. R. Liu, Biochim. Biophys. Acta, Proteins Proteomics, 2014, 1844, 1059-1070.

5 L. Davis and J. W. Chin, Nat. Rev. Mol. Cell Biol., 2012, 13, 168-182.

6 W. Wan, Y. Huang, Z. Wang, W. K. Russell, P.-J. Pai, D. H. Russell and W. R. Liu, Angew. Chem., Int. Ed., 2010, 49, 3211-3214.

7 K. Wang, W. H. Schmied and J. W. Chin, Angew. Chem., Int. Ed., 2012, 51, 2288-2297.

8 G. Srinivasan, C. M. James and J. A. Krzycki, Science, 2002, 296, 1459-1462.

9 C. Polycarpo, A. Ambrogelly, A. Berube, S. M. Winbush, J. A. McCloskey, P. F. Crain, J. L. Wood and D. Soll, Proc. Natl. Acad. Sci. U. S. A., 2004, 101, 12450-12454.

10 R. J. Ernst, T. P. Krogager, E. S. Maywood, R. Zanchi, V. Beránek, T. S. Elliott, N. P. Barry, M. H. Hastings and J. W. Chin, Nat. Chem. Biol., 2016, 12, 776-778. 
11 S. Han, A. Yang, S. Lee, H.-W. Lee, C. B. Park and H.-S. Park, Nat. Commun., 2017, 8, 14568.

12 A. Bianco, F. M. Townsley, S. Greiss, K. Lang and J. W. Chin, Nat. Chem. Biol., 2012, 8, 748-750.

13 S. Greiss and J. W. Chin, J. Am. Chem. Soc., 2011, 133, 1419614199.

14 F. Li, H. Zhang, Y. Sun, Y. Pan, J. Zhou and J. Wang, Angew. Chem., Int. Ed., 2013, 52, 9700-9704.

15 R. A. Mehl, J. C. Anderson, S. W. Santoro, L. Wang, A. B. Martin, D. S. King, D. M. Horn and P. G. Schultz, J. Am. Chem. Soc., 2003, 125, 935-939.

16 K. Ohtake, A. Sato, T. Mukai, N. Hino, S. Yokoyama and K. Sakamoto, J. Bacteriol., 2012, 194, 2606-2613.

17 T. Mukai, H. Hoshi, K. Ohtake, M. Takahashi, A. Yamaguchi, A. Hayashi, S. Yokoyama and K. Sakamoto, Sci. Rep., 2015, 5, 9699.

18 D. B. F. Johnson, J. Xu, Z. Shen, J. K. Takimoto, M. D. Schultz, R. J. Schmitz, Z. Xiang, J. R. Ecker, S. P. Briggs and L. Wang, Nat. Chem. Biol., 2011, 7, 779-786.

19 B. G. Fox and P. G. Blommel, in Current Protocols in Protein Science, John Wiley \& Sons, Inc., Hoboken, NJ, USA, 2009, ch. 5, pp. 5.23.1-5.23.18.

20 F. W. Studier, Protein Expression Purif., 2005, 41, 207-234.

21 H. K. Sreenath, C. A. Bingman, B. W. Buchan, K. D. Seder, B. T. Burns, H. V. Geetha, W. B. Jeon, F. C. Vojtik, D. J. Aceti, R. O. Frederick, G. N. Phillips and B. G. Fox, Protein Expression Purif., 2005, 40, 256-267.

22 Y.-S. Wang, X. Fang, H.-Y. Chen, B. Wu, Z. U. Wang, C. Hilty and W. R. Liu, ACS Chem. Biol., 2013, 8, 405-415.

23 K. A. Odoi, Y. Huang, Y. H. Rezenom and W. R. Liu, PLoS One, 2013, 8, e57035.

24 R. B. Cooley, P. A. Karplus and R. A. Mehl, ChemBioChem, 2014, 15, 1810-1819.

25 R. B. Cooley, J. L. Feldman, C. M. Driggers, T. A. Bundy, A. L. Stokes, P. A. Karplus and R. A. Mehl, Biochemistry, 2014, 53, 1916-1924.

26 A. Yamaguchi, T. Matsuda, K. Ohtake, T. Yanagisawa, S. Yokoyama, Y. Fujiwara, T. Watanabe, T. Hohsaka and K. Sakamoto, Bioconjugate Chem., 2016, 27, 198-206.

27 J. C. Peeler and R. A. Mehl, in Methods in molecular biology, Clifton, N.J., 2012, vol. 794, pp. 125-134.

28 J. M. Tharp, Y.-S. Wang, Y.-J. Lee, Y. Yang and W. R. Liu, ACS Chem. Biol., 2014, 9, 884-890.
29 J. T. Hammill, S. Miyake-Stoner, J. L. Hazen, J. C. Jackson and R. a. Mehl, Nat. Protoc., 2007, 2, 2601-2607.

30 F. Studier and B. A. Moffatt, J. Mol. Biol., 1986, 189, 113-130. 31 P. Neubauer, K. Hofmann, O. Holst, B. Mattiasson and P. Kruschke, Appl. Microbiol. Biotechnol., 1992, 36, 739-744. 32 C. a. Schneider, W. S. Rasband and K. W. Eliceiri, Nat. Methods, 2012, 9, 671-675.

33 J.-D. Pédelacq, S. Cabantous, T. Tran, T. C. Terwilliger and G. S. Waldo, Nat. Biotechnol., 2006, 24, 79-88.

34 H. Neumann, S. M. Hancock, R. Buning, A. Routh, L. Chapman, J. Somers, T. Owen-Hughes, J. van Noort, D. Rhodes and J. W. Chin, Mol. Cell, 2009, 36, 153-163.

35 H. Neumann, S. Y. Peak-Chew and J. W. Chin, Nat. Chem. Biol., 2008, 4, 232-234.

36 K. Lang, L. Davis, S. Wallace, M. Mahesh, D. J. Cox, M. L. Blackman, J. M. Fox and J. W. Chin, J. Am. Chem. Soc., 2012, 134, 10317-10320.

37 A. Gautier, D. P. Nguyen, H. Lusic, W. An, A. Deiters and J. W. Chin, J. Am. Chem. Soc., 2010, 132, 4086-4088.

38 D. P. Nguyen, T. Elliott, M. Holt, T. W. Muir and J. W. Chin, J. Am. Chem. Soc., 2011, 133, 11418-11421.

39 S. Virdee, P. B. Kapadnis, T. Elliott, K. Lang, J. Madrzak, D. P. Nguyen, L. Riechmann and J. W. Chin, J. Am. Chem. Soc., 2011, 133, 10708-10711.

40 E. Arbely, J. Torres-Kolbus, A. Deiters and J. W. Chin, J. Am. Chem. Soc., 2012, 134, 11912-11915.

41 V. M. D'souz and R. C. Holz, Biochemistry, 1999, 38, 1107911085.

42 S. C. Chai, W.-L. Wang and Q.-Z. Ye, J. Biol. Chem., 2008, 283, 26879-26885.

43 Z.-l. Yuan, Science, 2005, 307, 269-273.

44 Y. Tang, J. Luo, W. Zhang and W. Gu, Mol. Cell, 2006, 24, 827-839.

45 S. M. Sykes, H. S. Mellert, M. A. Holbert, K. Li, R. Marmorstein, W. S. Lane and S. B. McMahon, Mol. Cell, 2006, 24, 841-851.

46 E. Arbely, E. Natan, T. Brandt, M. D. Allen, D. B. Veprintsev, C. V. Robinson, J. W. Chin, A. C. Joerger and A. R. Fersht, Proc. Natl. Acad. Sci. U. S. A., 2011, 108, 8251-8256.

47 R. Vainer, S. Cohen, A. Shahar, R. Zarivach and E. Arbely, J. Mol. Biol., 2016, 428, 3013-3025.

48 B. J. Rauch, J. J. Porter, R. A. Mehl and J. J. Perona, Biochemistry, 2016, 55, 618-628. 